\title{
Inflation Targeting and Nonlinear Policy Rules: the Case of Asymmetric Preferences
}

\author{
Paolo Surico* \\ Bocconi University
}

February 2004

\begin{abstract}
This paper investigates the empirical relevance of a new framework for monetary policy analysis in which the decision makers are allowed to weight differently positive and negative deviations of inflation and output from the target values. Reduced-form and structural estimates of the central bank first order condition indicate that the preferences of the Fed have been highly asymmetric only before 1979, with the response to output contractions being larger than the response to output expansions of the same magnitude. This asymmetry is shown to induce an average inflation bias of $1.11 \%$ that appears to have substantially contributed to the great inflation of the 1960 s and 1970 s.
\end{abstract}

JEL Classification: E52, E58.

Key words: asymmetric objective, nonlinear monetary policy rules, average inflation bias

\footnotetext{
*I am grateful to Efrem Castelnuovo, Carlo Favero, Jordi Galí, Tommaso Monacelli, Anton Muscatelli, Roberto Perotti, Ulf Söderström, Guido Tabellini and participants at various seminars and conferences for very helpful feedbacks. Address for correspondence: Istituto di Economia Politica, Università Bocconi, Via Gobbi 5, 20136 Milan, Italy. E-mail: paolo.surico@uni-bocconi.it
} 


\section{Introduction}

A popular method of monetary model building is to regard policy interventions as the solution of an optimal control problem in which the central bank minimizes some quadratic criterion subject to a linear structure of the economy. The quadratic characteristic of the objective and the linear feature of the constraints give rise to a linear first order condition, usually referred to as a targeting rule (see Svensson, 1999), that describes the optimal response of the central bank to the developments in the economy. While the quadratic specification implies that monetary authorities evenly weight positive and negative deviations of inflation and output from the target values, such a modeling choice has been questioned by several practitioners at the policy committees of various central banks on the ground that it has little justification beyond analytical tractability. ${ }^{1}$

Blinder (1997, p. 6) argues that' academic macroeconomists tend to use quadratic loss functions for reason of mathematical convenience, without thinking much about their substantive implications. The assumption is not innocuous, [...] practical central bankers and academics would benefit from more serious thinking about the functional form of the loss function'. Describing his experience as Fed vice-Chairman Blinder (1998, pp. 19-20) pushes the argument even further and claims 'in most situations the central bank will take far more political heat when it tightens pre-emptively to avoid higher inflation than when it eases pre-emptively to avoid higher unemployment', suggesting that political pressures can induce asymmetric central bank interventions. Similar concerns appear to emerge also at other central banks like the ECB and in the occasion of an interest rate cut of 50 point basis Duisenberg (2001) states 'the maintenance of price stability remains our first priority. [...] today's action could be taken "without prejudice to price stability", and it thereby supported the other goals of EMU, such as economic growth'.

On the academic side, several recent studies explore novel mechanisms through which the costs of the business cycle can be asymmetric. Persson and Tabellini (1999) combine retrospective voting with imperfect information about the incumbent's talent to show that career concerned politicians can make reappointment more likely by endowing the central bank with an asymmetric objective that requires a larger monetary policy response in periods of

\footnotetext{
${ }^{1}$ The few notable exceptions include Rotemberg and Woodford (1999) and Woodford (2003, ch. 6), who show that the quadratic form can be obtained as a second order approximation of the representative agent's utility function.
} 
poor economic performance. ${ }^{2}$ Galí, Gertler and Lopez-Salido (2003a) construct a theoretical measure of welfare gap that is based on price and wage markups, and find that the costs of output fluctuations for the US have been historically large and asymmetric. Erosa and Ventura (2002) introduce transaction costs and heterogeneity in portfolio holdings in an otherwise neo-classical model and show that these frictions can make the costs of inflation variation asymmetric. Lastly, the psychology of choice reveals that people tend to place a greater weight on the prospect of losses than on the prospect of gains in decision making under uncertainty (see Kahneman and Tversky, 1979), suggesting that also policy makers, who aggregate over individual welfare, may be loss-averse.

Despite its intuitive appeal, only a few studies have attempted to identify asymmetric central bank behaviors and the relevance of this alternative framework remains to be assessed. Cukierman and Muscatelli (2003), Martin and Milas (2004), and Kim, Osborne and Sensier (2004) show some international evidence that supports the notion of nonlinear interest rate rules. Ruge-Murcia (2003 and 2004), and Cukierman and Gerlach (2003) adopt an inflation rate reaction function that is nonlinear in either inflation or the output gap, and using data for some OECD economy they favor the hypothesis of an asymmetric objective. Dolado, Maria-Dolores and Ruge-Murcia (2003) estimate an optimal interest rate rule that is drawn upon the existence of asymmetric preferences on inflation only, and find that US monetary policy can be characterized by a nonlinear function after 1983 .

This paper contributes to the literature on monetary policy rules in several respects. First, it proposes a general, potentially asymmetric specification for both the inflation and the output objectives that nests the quadratic form as a special case. Accordingly, the optimal policy rule is nonlinear if and only if the preferences of the central bank are asymmetric. Second, the analytical solution of the optimal control problem allows us to identify the degree of nonlinearity and asymmetry with respect to both objectives, a result that to our knowledge of the existing literature comes as new. Third, the model generates the testable prediction that the monetary authorities respond not only to the level of inflation and output gaps as suggested by Taylor (1993) but also to their squared values. Fourth, reduced-form and structural estimates of US monetary policy rules indicate that nonlinearity is a robust feature of the postwar data only before 1979 and with respect to the output gap. While this finding

\footnotetext{
${ }^{2}$ De Long (1997) forcefully argues that US monetary policy during the 1970s was highly sensitive to the political pressures for a higher money growth and lower interest rates, and provides extensive narrative evidence about the influence of Nixon's administration on the Chairmanship of Arthur Burns at the Fed.
} 
is consistent with the notion of a Fed's policy regime shift, it provides an explanation for the great inflation of the 1960s and 1970s as the model predicts that asymmetric preferences over the output gap generate an average inflation bias. The latter is found to move from $1.11 \%$ before 1979 to a value not statistically different from zero over the last two decades.

The road map of the paper is as follows. Section 2 presents the model and derives the interest rate rule as the first order condition of the central bank optimization problem. Section 3 reports the estimates of both the policy rule coefficients and the preference parameters, and conducts a robustness analysis. The following section shows that asymmetric preferences on the output gap induce an average inflation bias, and proposes a simple strategy to decompose the actual inflation mean into a target and a bias argument. Section 5 concludes.

\section{Theoretical model}

We assume that the central bank conducts monetary policy through a targeting rule according to the terminology of Svensson (1999). Thus, all available information are used to bring at each point in time the target variables in line with their targets by penalizing any future deviation of the former from the latter. The policy rule is modeled as the discretionary outcome of an intertemporal optimization problem in which the decision makers minimize a given criterion subject to the constraints provided by the structure of the economy. The optimizing device allows us to back out the objectives of the monetary authorities, which are unobserved, from the observed path of policy rates implying that evidence on the latter can be interpreted as informative about the former. Since our identification strategy relies on the estimation of a model-based specification for the reaction function, we challenge the assumption of symmetric policy preferences in the context of a popular framework for monetary policy analysis. This is a version of the New-Keynesian model of the business cycle derived in Yun (1996), and Woodford (2003, chs. 3 and 4), among many others. ${ }^{3}$

\subsection{The structure of the economy}

This subsection describes an aggregate, log-linearized version of the New-Keynesian forwardlooking model with sticky prices that has been recently summarized by Clarida, Galí and Gertler (1999). The evolution of the economy is compactly represented by the following two-

\footnotetext{
${ }^{3}$ Surico (2003) shows that both the theoretical and the empirical results obtained here using a New-Kynesian model are robust to the specification of a Lucas aggregate supply curve as structure of the economy.
} 
equation system:

$$
\begin{aligned}
& \pi_{t}=\theta E_{t} \pi_{t+1}+k y_{t}+\varepsilon_{t}^{s} \\
& y_{t}=E_{t} y_{t+1}-\varphi\left(i_{t}-E_{t} \pi_{t+1}\right)+\varepsilon_{t}^{d}
\end{aligned}
$$

Equation (1) captures the staggered feature of a Calvo-type world in which each firm adjusts its price with a constant probability in any given period, and independently from the time elapsed from the last adjustment. The discrete nature of price setting creates an incentive to adjust prices by more the higher is the future inflation expected at time $t$. The inflation level is $\pi_{t}$ whereas the output gap is denoted by $y_{t}$ and captures the movements in marginal costs associated with variations in excess demand. For analytical convenience, the aggregate supply curve is assumed purely forward-looking. Galí and Gertler (1999), Ireland (2001), Galí, Gertler and Lopez-Salido (2003b), and Smets and Wouters (2003a) provide empirical support for this choice as a good first approximation to the dynamics of US inflation.

Equation (2) is a standard Euler equation for consumption combined with the relevant market clearing condition. It basically brings the notion of consumption smoothing into an aggregate demand formulation by making the output gap a positive function of its future value and a negative function of the real interest rate, $i_{t}-E_{t} \pi_{t+1}$. Lastly, $\varepsilon_{t}^{s}$ and $\varepsilon_{t}^{d}$ are respectively cost and demand disturbances that obey an autoregressive, mean reverting process.

\subsection{An asymmetric specification of the loss function}

An important aspect of monetary policy making is that policy actions are taken before the realization of economic shocks and therefore before the variables in the system are determined. Accordingly, the problem of the central bank is to choose the interest rate at the beginning of period $t$ conditional upon the information available at the end of the previous period. This timing device is captured by the following intertemporal criterion:

$$
\operatorname{Min}_{\left\{i_{t}\right\}} E_{t-1} \sum_{\tau=0}^{\infty} \delta^{\tau} L_{t+\tau}
$$

where $\delta$ is the discount factor and $L$ stands for the period loss function.

Our framework differs from the conventional quadratic set up in that we employ a more general specification of the monetary authorities' objectives. Indeed, the quadratic form may approximate reasonably well a number of different functions and in the absence of a rigorous theoretical foundation any specific nonquadratic proposal is destined to be unsatisfactory 
against the wide range of plausible alternatives. Hence, rather than attempting to uncover the correct functional form of policy makers' preferences, we evaluate the symmetric quadratic setup upon the empirical merits of the monetary policy rule that this specification implies. With this descriptive scope in mind, we write $L_{t}$ as follows:

$$
L_{t}=\frac{1}{2}\left[\left(\pi_{t}-\pi^{*}\right)^{2}+\frac{\alpha}{3}\left(\pi_{t}-\pi^{*}\right)^{3}\right]+\frac{\lambda}{2}\left[y_{t}^{2}+\frac{\gamma}{3} y_{t}^{3}\right]+\frac{\mu}{2}\left(i_{t}-i^{*}\right)^{2}
$$

The coefficients $\lambda$ and $\mu$ represent the central bank's aversion towards output fluctuations around potential and towards interest rate level fluctuations around the target $i^{*}$. The policy preference towards inflation stabilization is normalized to one and therefore $\lambda$ and $\mu$ are expressed in relative terms. The inflation target is $\pi^{*}$ whereas the parameters $\alpha$ and $\gamma$ capture any asymmetry in the objective function of the monetary authorities.

The cubic specification (4) departures from the quadratic in that policy makers are allowed, but not required, to treat differently positive and negative deviations of inflation and output from the target. A negative value of $\gamma$ implies that, everything equals, an output contraction relative to the potential level is weighted more severely than an output expansion. To see this notice that whenever $y_{t}<0$ the cubic term, $\gamma y_{t}^{3}$, is positive and amplifies the penalty due to the quadratic component. Conversely, for values of output above potential the quadratic and the cubic terms move in opposite directions implying that a positive deviation of a given amount is associated with a smaller loss than a negative deviation of the same size. Figure 1 compares the standard quadratic with the asymmetric cubic function using the historical values of the output gap and the estimates of $\gamma$ reported below.

A similar reasoning holds for the coefficient $\alpha$ that captures any asymmetry in the policy preferences for stabilizing inflation around the target. However, if the monetary authorities are more concerned about overshooting $\pi^{*}$ rather than undershooting it, the value of $\alpha$ would be positive meaning that high inflation relative to the target is more costly than low inflation. It should be noted that while these sign predictions seem plausible given the sample we use, the cubic specification does not prevent $\alpha$ to be negative corresponding to a case in which the risk of deflation outweighs the risk of inflation. ${ }^{4}$

\footnotetext{
${ }^{4}$ The cubic specification can also be interpreted as some third-order approximation around $\left(\pi_{t}-\pi^{*}\right)=0$ and $y_{t}=0$ to the linex function proposed by Nobay and Peel (2003), and employed by Chadha and Schellekens (1999), Geraats (1999) and Ruge-Murcia (2003 and 2004). The advantage of using the cubic form as the primitive function is that it does not require any approximation of the optimal monetary policy rule. Nevertheless, for a realistic range of values for $\left(\pi_{t}-\pi^{*}\right)$ like $[-0.04,0.09]$ and for $y_{t}$ like $[-0.08,0.06]$, and given the estimates of $\alpha$ and $\gamma$ reported below, the cubic and the linex function behave very similarly.
} 
The cubic loss function nests the quadratic form as a special case such that $\alpha=\gamma=0$

corresponds to the symmetric parametrization $L_{t}=\frac{1}{2}\left[\left(\pi_{t}-\pi^{*}\right)^{2}+\lambda y_{t}^{2}+\mu\left(i_{t}-i^{*}\right)^{2}\right]$. The latter can be obtained as a second order approximation of the utility-based welfare function in a New-Keynesian model of the business cycle that involves a zero lower bound for nominal interest rate (see Woodford, 2003, ch. 6). Accordingly, the policy preferences would be functions of some primitive parameters of the model implying that potential evidence of asymmetries in the central bank objective could be tracked into evidence of asymmetries in the representative agent's utility. Indeed, as argued by Clarida, Galí and Gertler (1999), the representative agent approach can be misleading as a guide to welfare analysis and in the absence of complete markets it is likely that some groups suffer more in recessions than others. This suggests that an asymmetric utility-based specification of the loss function may be a desirable representation of the social costs associated with the business cycle.

\subsection{A nonlinear policy rule}

We solve for the optimal monetary policy under discretion. Because no endogenous state variable enters the model, the intertemporal problem reduces to a sequence of static optimization problems. This amounts to choosing in each period the instrument $i_{t}$ such as to minimize:

$$
E_{t-1}\left\{\frac{1}{2}\left[\left(\pi_{t}-\pi^{*}\right)^{2}+\frac{\alpha}{3}\left(\pi_{t}-\pi^{*}\right)^{3}\right]+\frac{\lambda}{2}\left[y_{t}^{2}+\frac{\gamma}{3} y_{t}^{3}\right]+\frac{\mu}{2}\left(i_{t}-i^{*}\right)^{2}\right\}+F_{t}
$$

subject to $\pi_{t}=k y_{t}+f_{t}$ and $y_{t}=-\varphi i_{t}+g_{t}$, where $F_{t} \equiv E_{t-1} \sum_{\tau=1}^{\infty} \delta^{\tau} L_{t+\tau}, f_{t} \equiv \theta E_{t} \pi_{t+1}+\varepsilon_{t}^{s}$ and $g_{t} \equiv E_{t} y_{t+1}+\varphi E_{t} \pi_{t+1}+\varepsilon_{t}^{d}$ are taken as given reflecting the fact that the monetary authorities cannot directly manipulate expectations. The first order condition reads

$$
-k \varphi E_{t-1}\left(\pi_{t}-\pi^{*}\right)-\lambda \varphi E_{t-1} y_{t}-\frac{\alpha k \varphi}{2} E_{t-1}\left(\pi_{t}-\pi^{*}\right)^{2}-\frac{\lambda \varphi \gamma}{2} E_{t-1} y_{t}^{2}+\mu\left(i_{t}-i^{*}\right)=0
$$

and it implicitly describes the optimal, potentially nonlinear response of the central bank to the developments in the economy. Equation (5) nests the linear form as a special case and whenever $\alpha=\gamma=0$ the reaction function collapses to an implicit interest rate rule of the type analyzed in Rudebusch (2002), and Clarida, Galí and Gertler (2000):

$$
-k \varphi E_{t-1}\left(\pi_{t}-\pi^{*}\right)-\lambda \varphi E_{t-1}\left(y_{t}\right)+\mu\left(i_{t}-i^{*}\right)=0
$$

This feature is attractive as it delivers a joint restriction on policy makers' preferences that can be formally tested for. The parameters $\alpha$ and $\gamma$ are indeed crucial for the analysis 
of optimal monetary policy not only because they introduce an asymmetric motive in the central bank objective function but also because, more importantly, they make nonlinear an otherwise conventional policy rule. This suggests that the hypothesis of symmetric central bank preferences can be tested simply by evaluating the functional form of the interest rate reaction function as the latter would correspond to test whether the structural parameters $\alpha$ and $\gamma$ are significantly different from zero.

\section{Empirical results}

This section reports the estimates and the relevant tests of the optimal policy rule. The analysis is conducted on US quarterly data spanning the period 1960:1-2003:2. The data set has been obtained in July 2003 from the web site of the Federal Reserve Bank of St. Louis and embodies alternative measures of inflation and output gap. In the baseline case, inflation is measured as the changes in the log of the consumer price index (CPI) while the output gap is constructed using the series of potential output provided by the Congressional Budget Office (CBO). Figure 2 plots the baseline series. As a way to provide a robustness check, we also report the results for two alternative measures of inflation and output gap, namely the GDP deflator and the Hodrick-Prescott filtered real GDP. ${ }^{5}$

We divide the full sample around the third quarter of 1979 which corresponds to the appointment of Paul Volcker as Fed Chairman. This lines up with a number of empirical studies that demonstrate a significant difference in the way monetary policy was conducted pre- and post-1979 (see Clarida, Galí and Gertler, 2000, and Favero and Rovelli, 2003 among many others). Moreover, we remove from the second sub-sample the period 1979:3-1982:3 when, as documented by Bernanke and Mihov (1998), the operating procedure of the Fed temporarily switched from federal funds rate to non-borrowed reserves targeting. Finally, we address the issue of subsample stability by re-evaluating the model over the Chairmanship of Alan Greenspan, namely 1987:3-2003:2.

\footnotetext{
${ }^{5}$ The use of a low frequency filter to obtain estimates of the target level of real activities does not contrast with the model-based definition of flexible-price level of output. As argued by Woodford (2003, ch. 7), the central bank can make society better off by accommodating technology and preference shocks while offsetting disturbances to inflation and wage mark-ups. In this vein, Smets and Wouters (2003b) show that if the monetary authorities wish to hedge against shocks of unknown nature, they would regard persistent disturbances as the only shocks affecting the target level of output. When applied to an estimated New-Keynesian model for the Euro area, they find that the counterfactual flexible-price level of output, which is the one responding to all non-monetary shocks in the economy, is indeed extremely volatile, whereas the target level of output, which is the one only affected by supply and demand disturbances, actually follows a relatively smooth path.
} 
We estimate a version of the central bank Euler equation using the Generalized Method of Moments (GMM) with an optimal weighting matrix that accounts for possible heteroskedasticity and serial correlation in the error terms (see Hansen, 1982). In practice, we employ a four lag Newey-West estimate of the covariance matrix. Starting from date $t-1$, four lags of the explanatory variables, the federal funds rates and the measure of inflation left out from the regression are included as instruments corresponding to a set of 19 overidentifying restrictions that can be tested for.

\subsection{Preliminary Analysis}

The quadratic terms in (5) stem from asymmetric central bank preferences but we cannot exclude in principle that some alternative source like a nonlinear Phillips curve might also return evidence of nonlinearity in the policy rule (see Schaling, 1999). A simple way to discriminate between nonquadratic objectives and nonlinear constraints is to perform the REgression Specification Error Test (RESET), which is designed to detect incorrect functional forms, on the New-Keynesian Phillips curve. Accordingly, we estimate equation (1) over the full sample using Instrumental Variables and a twelve-lag Newey-West variance covariance matrix. The set of instruments dated at time $t-1$ includes four lags of the GDP deflator inflation, the CBO output gap, the long-short interest rate spread, and the CPI inflation. When the squared, and then the squared and the cubes of the predictions $\hat{\pi}_{t}$ are added to the original equation, the corresponding F-tests show that the null hypothesis of nonmisspecification is not rejected. This suggests that the US aggregate supply curve is well approximated by a linear relation, consistently with the findings in Dolado, Maria-Dolores and Ruge-Murcia (2003), and Dolado, Maria-Dolores and Naveira (2004).

An additional form of nonlinearity comes from the policy makers' (mis)perception of the state of the economy. Suppose that on the basis of the estimates available in real-time the Fed believed for part of the sample that the output gap was larger than the revised data indicates. Then, the policy interventions during that period may appear surprisingly activist given the values of the gap from the 2003 vintage. However, using real-time data Orphanides (2004) finds that the Fed response to the output gap was actually more activist in the 1970s when the misperceptions on potential output turned out to be more severe. Moreover, Kuha and Temple (2003) show that measurement error in quadratic regressions tends to hide the presence of nonlinearities. In the view of these arguments, this paper takes an essential step 
towards asymmetric preferences by extending the available evidence on monetary policy rules using revised data.

A further reason for nonlinearity is associated with the point estimates of the natural rate of real activity. Meyer, Swanson and Wieland (2001) show that in periods of heightened uncertainty about the NAIRU, the central bank may face an incentive to move policy rates only for sufficiently large deviations of unemployment from the target. While potentially relevant, this hypothesis testing would require a real-time series for potential output such as to reflect the policy makers' beliefs about the state of the economy at the time decisions were taken. For reasons discussed above, however, we use the official estimates of potential output, which are actually revised by the $\mathrm{CBO}$ on a regular basis. As these revisions sensibly reduce the uncertainty about the historical measures of the output gap, this form of nonlinearity is likely to play only a marginal role in our analysis.

\subsection{Reduced-form estimates}

We solve equation (5) for $i_{t}$ and prior to GMM estimation we replace expectations with realized values. As customary in the empirical studies, we introduce a lagged dependent variable to capture interest rate smoothing for which a number of explanations are provided in the literature (see Woodford, 1999, Sack and Wieland, 2000, and Castelnuovo, 2003). Accordingly, we estimate the following policy rule:

$$
i_{t}=(1-\rho)\left[i^{*}+c_{1}\left(\pi_{t}-\pi^{*}\right)+c_{2} y_{t}+c_{3}\left(\pi_{t}-\pi^{*}\right)^{2}+c_{4}\left(y_{t}\right)^{2}\right]+\rho i_{t-1}+v_{t}
$$

where the coefficients are given by the expressions

$$
c_{1} \equiv \frac{k \varphi}{\mu}, \quad c_{2} \equiv \frac{\lambda \varphi}{\mu}, \quad c_{3} \equiv \frac{\alpha k \varphi}{2 \mu}, \quad c_{4} \equiv \frac{\lambda \varphi \gamma}{2 \mu}
$$

and the error term is defined as

$$
v_{t} \equiv-(1-\rho)\left\{\begin{array}{c}
c_{1}\left(\pi_{t}-E_{t-1} \pi_{t}\right)+c_{2}\left(y_{t}-E_{t-1} y_{t}\right)+ \\
+c_{3}\left[\pi_{t}^{2}-E_{t-1}\left(\pi_{t}\right)^{2}\right]+c_{4}\left[y_{t}^{2}-E_{t-1}\left(y_{t}\right)^{2}\right]
\end{array}\right\}
$$

The term in curly brackets is a linear combination of forecast errors and therefore $v_{t}$ is orthogonal to any variable in the information set available at time $t-1$.

Equation (6) makes clear that the reaction function parameters can only be interpreted as convolutions of the coefficients representing policy makers' preferences and those describing the structure of the economy. Although it is not possible to recover all structural parameters from 
a reduced-form single equation, the estimates of the policy rule can identify the asymmetric preferences as $\alpha=2 c_{3} / c_{1}$ and $\gamma=2 c_{4} / c_{2}$. In particular, the feedback coefficients $c_{3}$ and $c_{4}$ embody the relevant information such that the joint restriction $c_{3}=c_{4}=0$ with $c_{1} \neq 0$ and $c_{2} \neq 0$ implies $\alpha=\gamma=0$. Hence, testing the hypothesis $H_{0}^{\prime}: c_{3}=c_{4}=0$ in (6) is equivalent to testing the hypothesis $H_{0}: \alpha=\gamma=0$ in (5). Under the null of a linear reaction function, which fully corresponds to the null of symmetric preferences, the statistics has an asymptotic $\chi^{2}$ distribution with as many degrees of freedom as the number of restrictions, and it can be successfully evaluated through a standard Wald test. As we are considering the auxiliary null $H_{0}^{\prime}: c_{3}=c_{4}=0$ rather than the original hypothesis $H_{0}: \alpha=\gamma=0$, the statistics is usually referred to as Wald-type.

In the absence of further assumptions our method only identifies the structural parameter on output gap asymmetry, $\gamma$, but neither the one on inflation, $\alpha$, nor the target $\pi^{*}$, separately. As the focus of our analysis is on asymmetric preferences, we choose to fix a value for $\pi^{*}$. Specifically, we conduct a grid search in the $1 \%$ neighborhood of the subsample inflation mean, which is $4.5 \%$ for the pre- and $2.8 \%$ for the post-1979 period respectively, and we select the value that provides the best fit. Moreover, as restricting $i^{*}$ appears beneficial for the convergence of the optimization algorithm, we assume that the subsample average of the interest rate provides a reasonable approximation for the target.

Table 1 reports the GMM estimates of the interest rate rule coefficients and the asymmetric preference parameters for the baseline case, which corresponds to the CBO output gap and CPI inflation. The squared output gap term, $c_{4}$, is highly significant over the pre-Volcker regime in the second column but loses most of its explanatory power during the later period in the third column (disregard the last column for the time being). The squared inflation term, $c_{3}$, appears relatively more relevant in the post-Volcker sample, though it is never statistically different from zero at the $5 \%$ significance level.

The estimates of the asymmetric preferences parameters are recovered from the feedback coefficients and the standard errors are computed using the delta method. Interestingly, $\alpha$ and $\gamma$ take the expected signs and, in accord to the reduced-form estimates, the asymmetric preference on output is the significant parameter before $1979 .{ }^{6}$ Specifically, a 0.3 estimate of $\gamma$ implies on impact a 75 point basis cut of the interest rate in response to a negative $2 \%$ output

\footnotetext{
${ }^{6}$ The results are robust to letting the pre-Volcker sample begin in 1966:1 when the Federal funds rate first traded consistently above the discount rate.
} 
gap but only a 42 point basis rise in response to a positive $2 \%$ gap. By contrast, after 1982 both coefficients become of limited importance and the Wald-type statistics in the second but last row indicates that the null hypothesis of symmetric preferences is not rejected at the $5 \%$ significance level, although it is rejected at the $10 \%$ level.

Finally, in order to gauge the forecasting advantages of the nonlinear (as opposed to the linear) monetary policy rule, we perform a version of the Diebold and Mariano (1995) test, which is designed to detect any difference in the predictive accuracy of two competing forecasts. To this end, we first compute the dynamically simulated fitted values of the two models and then we calculate the corresponding root-mean-squared error (RMSE) over both sub-samples. The RMSE of the linear model is 0.96 in the pre-Volcker period and 0.65 in the post-Volcker period, while the values of the nonlinear model are 0.78 and 0.63 , respectively. The Diebold-Mariano test rejects the null hypothesis of no difference in the accuracy of the two specifications only during the pre-1979 regime, and it thus corroborates the results of the Wald-type tests for the presence of asymmetric preferences.

\subsection{Robustness checks}

We assess now in turn the robustness of our findings to subsample stability and to alternative measures of inflation and output gap. The last column of Table 1 displays the estimates for the sample 1987:3 - 2003:2, which corresponds to the tenure of Alan Greenspan as Fed Chairman. The squared inflation and output gaps do not have any explanatory power and translate into values of $\alpha$ and $\gamma$ that are not statistically different from zero at any conventional level. This holds true also for their joint significance as shown by the $p$-value of the Wald test. Moreover, the parameter on inflation takes now a negative sign consistently with the view that deflation may have recently become the most imminent risk for the Fed.

Table 2 reports the estimates obtained using, everything equals, the rate of change in the GDP deflator as measure of inflation. The squared terms line up with those in Table 1 and translate into meaningful preference parameters. Specifically, the coefficient on output gap, $\gamma$, always takes a negative sign and is significant only during the pre-Volcker era, while the coefficient on inflation, $\alpha$, is never statistically different from zero. Lastly, the Wald statistics confirm that asymmetric preferences matter before 1979, but not after 1982 .

We re-estimate the policy rule (6) using CPI inflation and the Hodrick-Prescott filtered output. The results are shown in Table 3 and they bear out those from the previous tables. 
A significant, negative value of the feedback coefficient $c_{4}$ over the first sub-sample maps into a significant, negative value of the asymmetric preference on output, whereas no asymmetry is detected for inflation. Once more, the null hypothesis of symmetric preferences is rejected only during the pre-Volcker regime.

\subsection{Structural estimates}

One econometric issue we must confront with is that, in small samples, nonlinear GMM may be sensitive to the normalization of the orthogonality conditions (see Fuhrer, Moore and Schuh, 1995). Moreover, specific parameterizations of the central bank Euler equation may allow us to draw direct inference on the structural parameters $\alpha$ and $\gamma$. To address these issues, we rearrange the targeting rule in two alternative forms that we view as most natural for the problem at hand. To keep consistency with the reduced-form specification, we introduce a lagged interest rate. The first specification normalizes the coefficient on the inflation level to unity:

$E_{t-1}\left\{\left[-\frac{\mu}{k \varphi}\left(i_{t}-i^{*}\right)+(1-\rho)\left(\left(\pi_{t}-\pi^{*}\right)+\frac{\lambda}{k} y_{t}+\frac{\alpha}{2}\left(\pi_{t}-\pi^{*}\right)^{2}+\frac{\gamma \lambda}{2 k} y_{t}^{2}\right)+\rho\left(i_{t-1}-i^{*}\right)\right] \mathbf{z}_{t-1}\right\}=0$

while the second normalizes the coefficient on the output gap level:

$E_{t-1}\left\{\left[-\frac{\mu}{\lambda \varphi}\left(i_{t}-i^{*}\right)+(1-\rho)\left(\frac{k}{\lambda}\left(\pi_{t}-\pi^{*}\right)+y_{t}+\frac{\alpha k}{2 \lambda}\left(\pi_{t}-\pi^{*}\right)^{2}+\frac{\gamma}{2} y_{t}^{2}\right)+\rho\left(i_{t-1}-i^{*}\right)\right] \mathbf{z}_{t-1}\right\}=0$

The latter specifications make it possible to estimate $\alpha$ and $\gamma$ directly, and since these are the structural parameters of the model, we refer to the values inferred upon (7) and (8) as structural estimates.

An advantage of these normalizations relative to the reduced-form (6) is that they do not implicitly impose a non-zero value for the weight on the interest rate level stabilization $\mu$. Moreover, to the extent that the inflation level and the output gap level significantly enter the central bank policy rule, as they virtually do in all empirical literature, the reducedform coefficient on the interest rate gap $\left(i_{t}-i^{*}\right)$ is informative about $\mu$ such that a positive, significant value of the convolutions $\left(\frac{\mu}{k \varphi}\right)$ and $\left(\frac{\mu}{\lambda \varphi}\right)$ implies a positive, significant value for $\mu$. While it is not possible to identify this policy preference parameter, we can evaluate whether it is statistically different from zero and since the test is performed on the convolution rather than on $\mu$ directly, we refer to it as a $t$-type test. 
We estimate $\alpha$ and $\gamma$ using nonlinear GMM and the set of instruments, $\mathbf{z}_{t-1}$, which includes the measures of inflation and output gap in the baseline case. The reduced-form coefficients are recovered from the estimates of the conditions (7) and (8) while the standard errors are computed using the delta method. The results for the first and the second normalization are reported in Table 4 and Table 5 respectively.

The structural estimates confirm, by and large, the reduced-form evidence. The implied $c_{i} \mathrm{~s}(i=1,2,3$ and 4$)$ are in most cases not statistically different from the estimates of the previous tables and they provide empirical support for the presence of asymmetric preferences. The squared variables do never have explanatory power with the exception of the output gap in the pre-Volcker sample, whose estimate, $c_{4}$, is negative and significant. The structural parameter $\alpha$ is never statistically different from zero whereas the significant values of $\gamma$ over the first sample are in line with the reduced-form estimates. In accord with the results of the previous tables, the joint null of symmetric central bank preferences, which is now directly tested on $\alpha$ and $\gamma$, is rejected before but not after 1979. Lastly, the t-type statistics for the null hypothesis $\mu=0$ indicate that the central bank penalizes also the fluctuations of the interest rate level and therefore they validate the restriction implicitly imposed by the reduced-form representation (6).

\subsection{Discussion}

It is useful at this point to compare our estimates with the results from some recent studies that also focus on the policy regime shift of 1979. Clarida, Galí and Gertler (2000) estimate a forward-looking linear reaction function for the pre-Volcker period and report values of 0.68 for the coefficient on CPI inflation (s.e.=0.06) and 0.28 for the coefficient on CBO output (s.e.= 0.08). Their estimates suggest that neglecting the squared output gap, which significantly enters our empirical specification with a negative sign, introduces a downward bias in the linear estimate. $^{7}$ Turning to the nonlinear specifications, Dolado, Maria-Dolores and Ruge-Murcia (2003) use a Clarida, Galí and Gertler-type of rule augmented with a generated regressor for the conditional variance of inflation and find no evidence for this form of nonlinearity. Kim, Osborne and Sensier (2004) use a semi-parametric method of estimation and show that only the asymmetry over the output gap has been sizable.

The post-Volcker estimates of the parameters on the inflation level and the output gap

\footnotetext{
${ }^{7}$ This result holds true also for the alternative measures of inflation and output gap.
} 
level are not statistically different from the values reported in Clarida, Galí and Gertler (2000), and therefore they confirm a limited role for nonlinearity during the last two decades. These results are consistent with those in Kim, Osborne and Sensier (2004) while they are only marginally so with those in Dolado, Maria-Dolores and Ruge-Murcia (2003). The absence of an output gap objective in the latter however seems a natural candidate to explain the difference. Lastly, we line up with earlier contributions in that the coefficient on the inflation level becomes bigger than one moving from the pre- to the post-1979 period.

\section{The average inflation bias}

The estimates of the previous section support the notion of a novel inflation bias due to Cukierman (2002). In the presence of an asymmetric objective over the output gap and uncertainty about the state of the economy, the monetary authorities face an incentive to respond more aggressively to output contractions of a given amount than to output expansions of the same magnitude. The reason is that the expected marginal benefit of a policy intervention is convex in the output gap, meaning that to satisfy the Euler equation and stimulate aggregate demand the policy makers cut the interest rate by more the worse the economic outlook is. As the private sector correctly anticipates such an incentive, the precautionary stance of the monetary policy generates a systematic boost in inflation expectations even though, unlike in Barro and Gordon (1983), the central bank targets output at potential. ${ }^{8}$

\subsection{A model-based measure of the inflation mean}

This section proposes a simple strategy to measure the asymmetric preferences induced inflation bias, which is defined as the difference between the model-based inflation mean and the inflation target. The resulting expression is isomorphic to the one that Surico (2003) derives as the difference between the optimal policies under discretion and under commitment using an asymmetric central bank objective and a Lucas aggregate supply.

On the basis of the empirical results presented in the previous section, we impose the

\footnotetext{
${ }^{8}$ In the theory of consumption, a precautionary motive emerges from the interaction between non-quadratic preferences and labor income risks such as to generate above-average saving rates in periods of high uncertainty. As shown by Kimball (1990), a necessary and sufficient condition for a precautionary saving is that the expected marginal utility be convex in consumption. Analogously here, the above-average inflation comes from the interaction between an asymmetric central bank objective and uncertainty about the state of the economy. Moreover, as the expected marginal loss is concave in the output gap, this motive can be thought as a precautionary demand for expansions.
} 
restriction $\alpha=0$ into the first order condition of the central bank optimization problem (5).The corresponding augmented targeting rule writes

$$
E_{t-1}\left\{\left[-\left(i_{t}-i^{*}\right)+(1-\rho)\left(c_{1}\left(\pi_{t}-\pi^{*}\right)+c_{2} y_{t}+c_{4} y_{t}^{2}\right)+\rho\left(i_{t-1}-i^{*}\right)\right] \mathbf{z}_{t-1}\right\}=0
$$

where the parameters are written in reduced-form for expositional convenience.

The maintained assumption that the target $i^{*}$ equals the sample mean of interest rate, combined with the empirically grounded restriction of a symmetric preference over inflation allow us to uniquely identify the inflation target. To see this, notice that the constant in the above expression becomes nothing but the convolution $\left(-c_{1} \pi^{*}\right) .9$ The average inflation bias can then be computed by taking the unconditional expectation of equation (9). According to the model, the inflation mean corresponds to the following expression:

$$
E\left(\pi_{t}\right)=\pi^{*}-\frac{c_{4}}{c_{1}} \sigma_{y}^{2}=\pi^{*}-\frac{\gamma \lambda}{2 k} \sigma_{y}^{2}
$$

where we have used the fact that the output gap has an unconditional distribution with zero mean and variance $\sigma_{y}^{2}$.

The average inflation bias arises here because policy preferences are asymmetric with respect to the output gap rather than because the desired level of output is above potential like in Barro and Gordon (1983). The distortion increases with the degree of asymmetry, and to the extent that the penalty associated to an output contraction is larger than the penalty associated to an output expansion of the same size, the model predicts $\gamma<0$. As $\lambda$ and $k$ are positive, the difference between the model-based inflation mean and the inflation target represents an inflation bias rather than a deflation bias. When $\gamma$ is equal to zero, the expected marginal benefit of a policy intervention becomes linear and the inflation bias disappears together with the precautionary motive.

The average inflation bias is proportional to the variance of the output gap and, as shown by the first equality in (10), it is inversely related to the inflation slope of the targeting rule (9). Hence, the model is general enough to confront the explanatory power of a change in the asymmetric preference parameter over the output gap, $\gamma$, with two alternative interpretations of the behavior of US inflation. The first is a shift in the response to the inflation level as captured by $c_{1}$. The second is a difference in the variance of the shocks as proxied by $\sigma_{y}^{2}$.

\footnotetext{
${ }^{9}$ It is worth noticing that the assumption on the interest rate target should bias, if any, the inflation target towards the sample mean of inflation. This suggests that our estimates are likely to understate the contribution of the asymmetric preferences induced bias to the actual mean of US inflation.
} 


\subsection{Measuring the bias}

We estimate equation (9) using GMM with a four lag Newey-West estimate of the covariance matrix. The measures of inflation and output gaps and the instrumental variables refer to the baseline case. The only difference relative to Table 1 is that, in line with the restriction $c_{3}=0$, the four lags of the squared inflation are not included here as instruments. The results are shown in Table 6 and they turn out to be sufficiently close to those reported in the previous tables that we do not comment further. The restrictions discussed above allows us to identify the inflation target, which is found to move from $3.61 \%$ before 1979 to a statistically lower $2.77 \%$ during the last two decades. Interestingly enough, this result contrasts with most of the empirical literature on monetary policy rules that, neglecting asymmetric preferences on the output gap and therefore imposing a linear reaction function, usually find a difference in $\pi^{*}$ across subsamples of two-to-three percentage points.

We use the estimates of table 6 to compute the inflation bias implied by the model, $\left(-\frac{c_{A}}{c_{1}} \sigma_{y}^{2}\right)$, and the delta method to obtain the standard errors. Table 7 displays the results. The average inflation bias, which is reported in the second row, is sizable and statistically different from zero only in the pre-Volcker period. The model-based inflation mean in the fourth row confirms that we effectively decompose the actual inflation mean into a target and a bias argument. Moreover, a shift in the policy preferences on output stabilization appears to account for a larger fraction of the difference in the sub-samples mean of inflation relative to a reduction in the inflation target.

The results in Table 6 and Table 7 suggest that while a different interest rate response to the inflation level, as described by the rise of $c_{1}$, and a more favorable macroeconomic environment, as summarized by the decline in the standard deviation of the output gap, have also played a role, a change in the policy preference on output from asymmetric to symmetric appears crucial to account for the observation that US inflation has been on average higher during the 1960s and 1970s than during the 1980s and 1990s.

\section{Conclusions}

The contribution of this paper is twofold. At the theoretical level it derives the analytical solution of the central bank optimization problem when the policy preferences are asymmetric in both inflation and output gaps, and the monetary transmission mechanism is New-Keynesian. 
The specification of the policy objectives is general enough to nest the quadratic form as a special case and therefore it translates into a potentially nonlinear targeting rule. This feature forms the basis of our hypothesis testing for the presence of asymmetric preferences as it allows to reversely engineer potential evidence of nonlinearities in the reaction function into evidence of asymmetries in the policy objective.

At the empirical level this paper shows that US monetary policy can be effectively characterized by a nonlinear policy rule only during the pre-Volcker regime, with the interest rate response to the state of the business cycle being the dominant type of nonlinearity. In particular, the Fed appears to have historically attached a larger weight to output contractions than to output expansions of the same magnitude such as to induce an average inflation bias of $1.11 \%$. The latter can account for a sizable fraction of the inflation rise observed during the 1960s and 1970s. These findings are robust across alternative measures of inflation and output gap, as well as across alternative estimation strategies.

Altogether, this paper provides empirical support for asymmetric preferences and suggests some caution about using symmetric loss functions as a guide to policy analysis. Promising strands of literature have recently emphasized that political pressures, labor market frictions and heterogeneity in portfolio holdings can make the costs of business fluctuations and inflation variation asymmetric. Along these lines, a stimulating avenue for future research is to derive an utility-based welfare function within richer models of the business cycle in order to provide a formal microfoundation for an asymmetric central bank objective. 


\section{References}

Barro, R.J. and D. Gordon, 1983, A Positive Theory of Monetary Policy in a Natural Rate Model, Journal of Political Economy 91, 589-610.

Bernanke, B. and I. Mihov, 1998, Measuring Monetary Policy, Quarterly Journal of Economics 63, 869-902.

Blinder, A., 1998, Central Banking in Theory and Practice, (Mit press).

Blinder, A., 1997, Distinguished Lecture on Economics and Government: What Central Bankers Could Learn from Academics and Viceversa, Journal of Economic Perspective 11, 3-19.

Castelnuovo, E., 2003, Squeezing the Interest Rate Smoothing Weight with an Hybrid Expectations Model, FEEM working paper No. 06.

Chadha, J.S. and P. Schellekens, 1999, Monetary policy loss functions: two cheers for the quadratic, DAE Working Paper 99/20.

Clarida, R., J. Galí and M. Gertler, 2000, Monetary Policy Rules and Macroeconomic Stability: Evidence and Some Theory, Quarterly Journal of Economics 115, 147-180.

Clarida, R., J. Galí and M. Gertler, 1999, The Science of Monetary Policy: A New Keynesian Perspective, Journal of Economic Literature 37, 1661-1707.

Cukierman, A, and S. Gerlach, 2003, The Inflation Bias Revisited: Theory and Some International Evidence, The Manchester School 71, 541-565.

Cukierman, A, and A. Muscatelli, 2003, Do Central Banks have Precautionary Demands for Expansions and for Price Stability? Theory and Evidence, mimeo, Tel-Aviv University.

Cukierman, A., 2002, Are Contemporary Central Banks Transparent about Economic Models and Objectives and What Difference Does it Make?, Federal Reserve Bank of St. Louis Review 84, 15-45.

De Long, J.B., 1997, America's Peacetime Inflation: the 1970s, in: Romer, C.D. and D.H. Romer, eds., Reducing Inflation: Motivation and Strategy, (Chicago University press).

Diebold, F.X., and R.S. Mariano, 1995, Comparing Predictive Accuracy, Journal of Business and Economic Statistics 13, 253-263.

Dolado, J.J., R. Maria-Dolores and M. Naveira, 2004, Are Monetary-Policy Reaction Functions Asymmetric? The Role of Nonlinearity in the Phillips Curve, European Economic Review, forthcoming.

Dolado, J.J., R. Maria-Dolores and F.J. Ruge-Murcia, 2003, Nonlinear Monetary Policy Rules: Some New Evidence for the US, mimeo, Université de Montrèal.

Duisenberg, W.F., 2001, Introductory Statement to the Press Conference on 8 November. 
Erosa, A. and G. Ventura, 2002, On Inflation as a Regressive Consumption Tax, Journal of Monetary Economics 49, 761-795.

Favero, C.A. and R. Rovelli, 2003, Macroeconomic Stability and the Preferences of the Fed: A Formal Analysis, 1961-98, Journal of Money, Credit and Banking 35, 545-556.

Fuhrer, J.C., G.R. Moore and S.D. Schuh, 1995, Estimating the Linear-Quadratic Inventory Model: Maximum Likelihood versus Generalized Method of Moments, Journal of Monetary Economics 35, 115-157.

Galí, J., M. Gertler and J.D. Lopez-Salido, 2003a, Markups, Gaps, and the Welfare Costs of Business Fluctuations, mimeo, Universitat Pompeu Fabra.

Galí, J., M. Gertler and J.D. Lopez-Salido, 2003b, Robustness of the Estimates of the Hybrid New Keynesian Phillips Curve, mimeo, Universitat Pompeu Fabra.

Galí, J. and M. Gertler, 1999, Inflation Dynamics: A Structural Econometric Analysis, Journal of Monetary Economics 44, 195-222.

Geraats, P., 1999, Inflation and Its Variation: An Alternative Explanation, CIDER Working Paper C99-105.

Hansen, L.P., 1982, Large Sample Properties of Generalized Method of Moments Estimators. Econometrica 50, 1029-1054.

Ireland, P., 2001, Sticky-Price Models of the Business Cycle: Specification and Stability, Journal of Monetary Economics 47, 3-18.

Kahneman, D. and A., Tversky, 1979, Prospect Theory: An Analysis of Decision under Risk, Econometrica 47, 263-292.

Kim, D.H., D.R. Osborne and M. Sensier, 2004, Nonlinearity in the Fed's Monetary Policy Rule, Journal of Applied Econometrics, forthcoming.

Kimball, M.S., 1990, Precautionary Saving in the Small and the Large, Econometrica 58, 53-73.

Kuha, J. and J. Temple, 2003, Covariate Measurement Error in Quadratic Regression, International Statistical Review 71, 131-150.

Martin, C. and C. Milas, 2004, Modelling Monetary Policy: Inflation Targeting in Practice, Economica, forthcoming.

Meyer, L.H., Swanson, E.T., and V. Wieland, 2001, NAIRU Uncertainty and Nonlinear Policy Rules, American Economic Review 91, 226-231.

Nobay, R. and D. Peel, 2003, Optimal Discretionary Monetary Policy in a Model of Asymmetric Central Bank Preferences, Economic Journal 113, 657-665.

Orphanides, A., 2004, Monetary Policy Rules, Macroeconomic Stability and Inflation: a View from the Trenches, Journal of Money, Credit and Banking, forthcoming. 
Persson, T., and G. Tabellini, 1999, Political Economics and Macroeconomic Policy, in: Taylor, J.B. and M. Woodford, eds., Handbook of Macroeconomics 1, (North-Holland).

Rotemberg, J.J. and M. Woodford, M., 1999, Interest Rate Rules in an Estimated Sticky Price Model, in: Taylor, J.B., ed., Monetary Policy Rules, (Chicago University press).

Rudebusch, G.D., 2002, Term Structure Evidence on Interest Rate Smoothing and Monetary Policy Inertia, Journal of Monetary Economics 49, 1161-1187.

Ruge-Murcia, F.J., 2004, The Inflation Bias when the Central Banker Targets the Natural Rate of Unemployment, European Economic Review 48, 91-107.

Ruge-Murcia, F.J., 2003, Inflation Targeting under Asymmetric Preferences, Journal of Money, Credit and Banking 35, 763-785.

Sack, B. and V. Wieland, 2000, Interest-Rate Smoothing and Optimal Monetary Policy: a Review of Recent Empirical Evidence, Journal of Economics and Business, 52, 205-228.

Schaling, E., 1999, The Non-Linear Phillips Curve and Inflation Forecast Targeting, Bank of England working paper No 98.

Smets, F. and R. Wouters, 2003a, Shocks and Frictions in US Business Cycle: a Bayesian DSGE Approach, mimeo, European Central Bank.

Smets, F. and R. Wouters, 2003b, Output Gaps: Theory versus Practice, mimeo, European Central Bank.

Surico, P., 2003, Measuring the Time-Inconsistency of US Monetary Policy, European Central Bank working paper No. 291.

Svensson, L.E.O., 1999, Inflation Targeting as a Monetary Policy Rule, Journal of Monetary Economics, 43, 607-654.

Taylor, J.B., 1993, Discretion versus Policy Rules in Practice, Carnegie-Rochester conference series on public policy 39, 195-214.

Woodford, M., 2003, Interest and Prices: Foundations of a Theory of Monetary Policy, forthcoming, (Princeton University Press).

Woodford, M., 1999, Optimal Monetary Policy Inertia, NBER working paper No 7261.

Yun, T., 1996, Nominal Price Rigidity, Money Supply Endogeneity, and Business Cycles, Journal of Monetary Economics 37, 345-370. 
Table 1: Reduced-form Estimates

- baseline measures of inflation and output gap -

1960:1-1979:2 1982:4 2003:2 1987:3-2003:2

\begin{tabular}{|c|c|c|c|}
\hline$c 1$ & $\begin{array}{l}0.80^{* *} \\
(0.06)\end{array}$ & $\begin{array}{l}1.45^{* *} \\
(0.22)\end{array}$ & $\begin{array}{l}2.74 * * \\
(0.34)\end{array}$ \\
\hline$c 2$ & $\begin{array}{l}0.79 * * \\
(0.11)\end{array}$ & $\begin{array}{l}0.95^{* * *} \\
(0.17)\end{array}$ & $\begin{array}{l}2.15 * * \\
(0.23)\end{array}$ \\
\hline$c 3$ & $\begin{array}{c}0.01 \\
(0.01)\end{array}$ & $\begin{array}{c}0.198 \\
(0.101)\end{array}$ & $\begin{array}{l}-0.19 \\
(0.10)\end{array}$ \\
\hline$c 4$ & $\begin{array}{l}-0.11^{* *} \\
(0.02)\end{array}$ & $\begin{array}{l}-0.041 \\
(0.023)\end{array}$ & $\begin{array}{l}-0.06 \\
(0.08)\end{array}$ \\
\hline$\rho$ & $\begin{array}{l}0.63 * * \\
(0.04)\end{array}$ & $\begin{array}{l}0.80 * * \\
(0.02)\end{array}$ & $\begin{array}{l}0.85 * * \\
(0.02)\end{array}$ \\
\hline$i^{*}$ & $\begin{array}{c}5.4 \\
-\end{array}$ & $\begin{array}{c}6.0 \\
-\end{array}$ & $\begin{array}{c}5.3 \\
-\end{array}$ \\
\hline$\pi^{*}$ & $\begin{array}{l}4.0 \\
-\end{array}$ & $\begin{array}{l}2.9 \\
-\end{array}$ & $\begin{array}{c}2.4 \\
-\end{array}$ \\
\hline$\alpha$ & $\begin{array}{c}0.01 \\
(0.03)\end{array}$ & $\begin{array}{c}0.25 \\
(0.13)\end{array}$ & $\begin{array}{l}-0.13 \\
(0.07)\end{array}$ \\
\hline$\gamma$ & $\begin{array}{l}-0.29 * * \\
(0.03)\end{array}$ & $\begin{array}{l}-0.09 \\
(0.05)\end{array}$ & $\begin{array}{l}-0.05 \\
(0.08)\end{array}$ \\
\hline$W(2) p$-value & 0.000 & 0.078 & 0.121 \\
\hline J(19) p-value & 0.960 & 0.874 & 0.963 \\
\hline
\end{tabular}

Specification: $i_{t}=(1-\rho)\left[i^{*}+c_{1}\left(\pi_{t}-\pi^{*}\right)+c_{2} y_{t}+c_{3}\left(\pi_{t}-\pi^{*}\right)^{2}+c_{4} y_{t}^{2}\right]+\rho i_{t-1}+v_{t}$

Notes: Standard errors using a four lag Newey-West covariance matrix are reported in brackets. Inflation is measured as the change in the consumer price index (cpi) and the output gap is obtained using the CBO potential output. The instrument set includes four lags of cpi inflation, squared cpi inflation, cbo output gap, squared cbo output gap, the fed funds rate and the rate of change in the gdp deflator. The asymmetric preference parameters are computed as $\alpha=2 c_{3} / c_{1}$ and $\gamma=2 c_{4} / c_{2}$ while the standard errors are obtained using the delta method. $W(n)$ refers to the Wald-type statistics of the test for $n$ parameter restrictions, which is distributed as a $\chi^{2}(n)$ under the joint null hypothesis $\mathrm{c} 3=\mathrm{c} 4=0$. The latter is equivalent to the original null of symmetric central bank preferences, $\alpha=\gamma=0$. $J(m)$ refers to the statistics of Hansen's test for $m$ overidentifying restrictions which is distributed as a $\chi^{2}(m)$ under the null hypothesis of valid overidentifying restrictions. The superscript $* *$ and $*$ denote the rejection of the null hypothesis that the true coefficient is zero at the 1 percent and 5 percent significance levels, respectively. 
Table 2: Reduced-form Estimates

- alternative measure of inflation -

1960:1 - 1979:2

$1982: 42003: 2$

\begin{tabular}{|c|c|c|}
\hline$c 1$ & $\begin{array}{l}0.81^{* *} \\
(0.08)\end{array}$ & $\begin{array}{l}3.29 * * \\
(0.63)\end{array}$ \\
\hline$c 2$ & $\begin{array}{l}1.07^{* *} \\
(0.13)\end{array}$ & $\begin{array}{l}1.13^{* *} \\
(0.39)\end{array}$ \\
\hline$c 3$ & $\begin{array}{c}0.03 \\
(0.02)\end{array}$ & $\begin{array}{c}0.76 \\
(0.55)\end{array}$ \\
\hline$c 4$ & $\begin{array}{l}-0.18 * * \\
(0.02)\end{array}$ & $\begin{array}{l}-0.25 \\
(0.14)\end{array}$ \\
\hline$\rho$ & $\begin{array}{l}0.65 * * \\
(0.04)\end{array}$ & $\begin{array}{l}0.89 * * \\
(0.04)\end{array}$ \\
\hline$i^{*}$ & $\begin{array}{c}5.4 \\
-\end{array}$ & $\begin{array}{c}6.0 \\
-\end{array}$ \\
\hline$\pi^{*}$ & $\begin{array}{c}3.7 \\
-\end{array}$ & $\begin{array}{c}2.6 \\
-\end{array}$ \\
\hline$\alpha$ & $\begin{array}{c}0.08 \\
(0.06)\end{array}$ & $\begin{array}{c}0.46 \\
(0.31)\end{array}$ \\
\hline$\gamma$ & $\begin{array}{l}-0.34 * * \\
(0.02)\end{array}$ & $\begin{array}{l}-0.45 \\
(0.30)\end{array}$ \\
\hline$W(2) p$-value & 0.000 & 0.194 \\
\hline J(19) p-value & 0.959 & 0.985 \\
\hline
\end{tabular}

Specification: $i_{t}=(1-\rho)\left[i^{*}+c_{1}\left(\pi_{t}-\pi^{*}\right)+c_{2} y_{t}+c_{3}\left(\pi_{t}-\pi^{*}\right)^{2}+c_{4} y_{t}^{2}\right]+\rho i_{t-1}+v_{t}$

Notes: Standard errors using a four lag Newey-West covariance matrix are reported in brackets. Inflation is measured as the rate change in the gdp deflator and the output gap is obtained using the CBO potential output. The instrument set includes four lags of gdp inflation, squared gdp inflation, cbo output gap, squared cbo output gap, the fed funds rate and cpi inflation. The asymmetric preference parameters are computed as $\alpha=2 c_{3} / c_{1}$ and $\gamma=2 c_{4} / c_{2}$ while the standard errors are obtained using the delta method. $W(n)$ refers to the Wald-type statistics of the test for $n$ parameter restrictions, which is distributed as a $\chi^{2}(n)$ under the joint null hypothesis $\mathrm{c} 3=\mathrm{c} 4=0$. The latter is equivalent to the original null of symmetric central bank preferences, $\alpha=\gamma=0 . J(m)$ refers to the statistics of Hansen's test for $m$ overidentifying restrictions which is distributed as a $\chi^{2}(m)$ under the null hypothesis of valid overidentifying restrictions. The superscript $* *$ and $*$ denote the rejection of the null hypothesis that the true coefficient is zero at the 1 percent and 5 percent significance levels, respectively. 


\begin{tabular}{|c|c|c|}
\hline$c 1$ & $\begin{array}{l}0.67^{* *} \\
(0.09)\end{array}$ & $\begin{array}{l}2.63^{* *} \\
(0.34)\end{array}$ \\
\hline$c 2$ & $\begin{array}{l}1.45^{* *} \\
(0.31)\end{array}$ & $\begin{array}{l}2.17 * * \\
(0.35)\end{array}$ \\
\hline$c 3$ & $\begin{array}{l}-0.02 \\
(0.02)\end{array}$ & $\begin{array}{c}0.07 \\
(0.18)\end{array}$ \\
\hline$c 4$ & $\begin{array}{l}-0.17 * * \\
(0.04)\end{array}$ & $\begin{array}{l}-0.19 \\
(0.10)\end{array}$ \\
\hline$\rho$ & $\begin{array}{l}0.72 * * \\
(0.05)\end{array}$ & $\begin{array}{l}0.83 * * \\
(0.02)\end{array}$ \\
\hline$i^{*}$ & $\begin{array}{c}5.4 \\
-\end{array}$ & $\begin{array}{c}6.0 \\
-\end{array}$ \\
\hline$\pi^{*}$ & $\begin{array}{l}4.1 \\
-\end{array}$ & $\begin{array}{l}2.9 \\
-\end{array}$ \\
\hline$\alpha$ & $\begin{array}{l}-0.06 \\
(0.04)\end{array}$ & $\begin{array}{c}0.06 \\
(0.13)\end{array}$ \\
\hline$\gamma$ & $\begin{array}{l}-0.25^{* *} \\
(0.07)\end{array}$ & $\begin{array}{c}-0.18 \\
(0.095)\end{array}$ \\
\hline$W(2) p$-value & 0.000 & 0.161 \\
\hline J(19) p-value & 0.969 & 0.895 \\
\hline
\end{tabular}

Specification: $i_{t}=(1-\rho)\left[i^{*}+c_{1}\left(\pi_{t}-\pi^{*}\right)+c_{2} y_{t}+c_{3}\left(\pi_{t}-\pi^{*}\right)^{2}+c_{4} y_{t}^{2}\right]+\rho i_{t-1}+v_{t}$

Notes: Standard errors using a four lag Newey-West covariance matrix are reported in brackets. Inflation is measured as changes in the cpi and the output gap is obtained with the Hodrick-Prescott $(\mathrm{H}-\mathrm{P})$ filter (smoothing parameter $=1600)$. The instrument set includes four lags of cpi inflation, squared cpi inflation, H-P output gap, squared H-P output gap, the fed funds rate and gdp inflation. The asymmetric preference parameters are computed as $\alpha=2 c_{3} / c_{1}$ and $\gamma=2 c_{4} / c_{2}$ while the standard errors are obtained using the delta method. $W(n)$ refers to the Wald-type statistics of the test for $n$ parameter restrictions, which is distributed as a $\chi^{2}(n)$ under the joint null hypothesis $\mathrm{c} 3=\mathrm{c} 4=0$. The latter is equivalent to the original null of symmetric central bank preferences, $\alpha=\gamma=0$. $J(m)$ refers to the statistics of Hansen's test for $m$ overidentifying restrictions which is distributed as a $\chi^{2}(m)$ under the null hypothesis of valid overidentifying restrictions. The superscript $* *$ and $*$ denote the rejection of the null hypothesis that the true coefficient is zero at the 1 percent and 5 percent significance levels, respectively. 
Table 4: Structural Estimates

- baseline normalization of the orthogonality conditions -

1960:1 - 1979:2

$1982: 42003: 2$

\begin{tabular}{|c|c|c|}
\hline$c 1$ & $\begin{array}{l}0.96^{* *} \\
(0.03)\end{array}$ & $\begin{array}{l}1.35^{* *} \\
(0.04)\end{array}$ \\
\hline$c 2$ & $\begin{array}{l}1.15^{* *} \\
(0.16)\end{array}$ & $\begin{array}{l}0.34 * * \\
(0.08)\end{array}$ \\
\hline$c 3$ & $\begin{array}{c}0.03 \\
(0.02)\end{array}$ & $\begin{array}{c}0.13 \\
(0.11)\end{array}$ \\
\hline$c 4$ & $\begin{array}{l}-0.17 * * \\
(0.03)\end{array}$ & $\begin{array}{l}-0.01 \\
(0.01)\end{array}$ \\
\hline$\rho$ & $\begin{array}{c}0.70^{* *} \\
(0.04)\end{array}$ & $\begin{array}{c}0.73 * * \\
(0.02)\end{array}$ \\
\hline$i^{*}$ & $\begin{array}{l}5.4 \\
-\end{array}$ & $\begin{array}{c}6.0 \\
-\end{array}$ \\
\hline$\pi^{*}$ & $\begin{array}{l}4.2 \\
-\end{array}$ & $\begin{array}{c}2.5 \\
-\end{array}$ \\
\hline$\alpha$ & $\begin{array}{c}0.05 \\
(0.04)\end{array}$ & $\begin{array}{c}0.20 \\
(0.18)\end{array}$ \\
\hline$\gamma$ & $\begin{array}{l}-0.29 * * \\
(0.02)\end{array}$ & $\begin{array}{l}-0.06 \\
(0.10)\end{array}$ \\
\hline $\begin{array}{c}\text { t-type statistics } \\
\text { p-value }\end{array}$ & 0.000 & 0.000 \\
\hline$W(2) p$-value & 0.000 & 0.530 \\
\hline$J(19) p$-value & 0.950 & 0.895 \\
\hline
\end{tabular}

Specification:

$E_{t-1}\left\{\left[-\frac{\mu}{\kappa \varphi}\left(i_{t}-i^{*}\right)+(1-\rho)\left(\left(\pi_{t}-\pi^{*}\right)+\frac{\lambda}{\kappa} y_{t}+\frac{\alpha}{2}\left(\pi_{t}-\pi^{*}\right)^{2}+\frac{\gamma \lambda}{2 \kappa} y_{t}^{2}\right)+\rho\left(i_{t-1}-i^{*}\right)\right] \mathrm{z}_{\mathrm{t}-1}\right\}=0$

Notes: This table reports the nonlinear GMM estimates of the structural parameters $\alpha$ and $\gamma$. The estimates of the reduced-form coefficients are recovered from the estimates of the structural parameters while the standard errors are computed using the delta method. Inflation, output gap and the instrument set $\mathrm{z}_{\mathrm{t}-1}$ correspond to the baseline measures described in the notes to Table 1 . The t-type test refers to the null hypothesis $(\mu / \kappa \varphi)=0$. $W(n)$ refers to the Wald-type statistics of the test for $n$ parameter restrictions, which is distributed as a $\chi^{2}(n)$ under the joint null hypothesis $\alpha=\gamma=0 . J(m)$ refers to the statistics of Hansen's test for $m$ overidentifying restrictions which is distributed as a $\chi^{2}(m)$ under the null hypothesis of valid overidentifying restrictions. The superscript $* *$ and $*$ denote the rejection of the null hypothesis that the true coefficient is zero at the 1 percent and 5 percent significance levels, respectively. 
Table 5: Structural Estimates

- alternative normalization of the orthogonality conditions -

1960:1 - 1979:2

$1982: 42003: 2$

\begin{tabular}{|c|c|c|}
\hline$c 1$ & $\begin{array}{l}0.79 * \\
(0.08)\end{array}$ & $\begin{array}{l}3.64 * * \\
(0.77)\end{array}$ \\
\hline$c 2$ & $\begin{array}{l}1.11 * * \\
(0.06)\end{array}$ & $\begin{array}{l}1.08 * * \\
(0.03)\end{array}$ \\
\hline$c 3$ & $\begin{array}{c}0.01 \\
(0.02)\end{array}$ & $\begin{array}{c}0.53 \\
(0.40)\end{array}$ \\
\hline$c 4$ & $\begin{array}{l}-0.17 * * \\
(0.01)\end{array}$ & $\begin{array}{l}-0.04 \\
(0.05)\end{array}$ \\
\hline$\rho$ & $\begin{array}{l}0.65^{* *} \\
(0.02)\end{array}$ & $\begin{array}{l}0.90^{* *} \\
(0.02)\end{array}$ \\
\hline$i^{*}$ & $\begin{array}{l}5.4 \\
-\end{array}$ & $\begin{array}{c}6.0 \\
-\end{array}$ \\
\hline$\pi^{*}$ & $\begin{array}{l}4.1 \\
-\end{array}$ & $\begin{array}{c}2.5 \\
-\end{array}$ \\
\hline$\alpha$ & $\begin{array}{c}0.03 \\
(0.04)\end{array}$ & $\begin{array}{c}0.29 \\
(0.22)\end{array}$ \\
\hline$\gamma$ & $\begin{array}{l}-0.31 * * \\
(0.02)\end{array}$ & $\begin{array}{l}-0.06 \\
(0.10)\end{array}$ \\
\hline $\begin{array}{c}\text { t-type statistics } \\
\text { p-value }\end{array}$ & 0.000 & 0.000 \\
\hline$W(2) p$-value & 0.000 & 0.423 \\
\hline$J(19) p$-value & 0.949 & 0.876 \\
\hline
\end{tabular}

Specification:

$E_{t-1}\left\{\left[-\frac{\mu}{\lambda \varphi}\left(i_{t}-i^{*}\right)+(1-\rho)\left(\frac{\kappa}{\lambda}\left(\pi_{t}-\pi^{*}\right)+y_{t}+\frac{\alpha \kappa}{2 \lambda}\left(\pi_{t}-\pi^{*}\right)^{2}+\frac{\gamma}{2} y_{t}^{2}\right)+\rho\left(i_{t-1}-i^{*}\right)\right] \mathrm{z}_{\mathrm{t}-1}\right\}=0$

Notes: This table reports the nonlinear GMM estimates of the structural parameters $\alpha$ and $\gamma$. The estimates of the reduced-form coefficients are recovered from the estimates of the structural parameters while the standard errors are computed using the delta method. Inflation, output gap and the instrument set $\mathrm{z}_{\mathrm{t}-1}$ correspond to the baseline measures described in the notes to Table 1 . The t-type test refers to the null hypothesis $(\mu / \lambda \varphi)=0$. $W(n)$ refers to the Wald-type statistics of the test for $n$ parameter restrictions, which is distributed as a $\chi^{2}(n)$ under the joint null hypothesis $\alpha=\gamma=0$. $J(m)$ refers to the statistics of Hansen's test for $m$ overidentifying restrictions which is distributed as a $\chi^{2}(m)$ under the null hypothesis of valid overidentifying restrictions. The superscript $* *$ and $*$ denote the rejection of the null hypothesis that the true coefficient is zero at the 1 percent and 5 percent significance levels, respectively. 
Table 6: Inferring the Inflation Target

- baseline measures of inflation and output gap -

$$
\text { 1960:1-1979:2 }
$$

1982:4 2003:2

\begin{tabular}{|c|c|c|}
\hline$c 1$ & $\begin{array}{l}0.82^{* *} \\
(0.06)\end{array}$ & $\begin{array}{l}2.60 * * \\
(0.72)\end{array}$ \\
\hline$c 2$ & $\begin{array}{l}0.84 * * \\
(0.19)\end{array}$ & $\begin{array}{c}0.97 * \\
(0.48)\end{array}$ \\
\hline$c 3$ & $\begin{array}{c}0.00 \\
-\end{array}$ & $\begin{array}{c}0.00 \\
-\end{array}$ \\
\hline$c 4$ & $\begin{array}{l}-0.13 * * \\
(0.04)\end{array}$ & $\begin{array}{l}-0.07 \\
(0.09)\end{array}$ \\
\hline$\rho$ & $\begin{array}{l}0.68 * * \\
(0.06)\end{array}$ & $\begin{array}{l}0.89 * * \\
(0.04)\end{array}$ \\
\hline$i^{*}$ & $\begin{array}{c}5.4 \\
-\end{array}$ & $\begin{array}{c}6.0 \\
-\end{array}$ \\
\hline$\pi^{*}$ & $\begin{array}{l}3.61 * * \\
(0.31)\end{array}$ & $\begin{array}{l}2.77 * * \\
(0.25)\end{array}$ \\
\hline$\alpha$ & $\begin{array}{c}0.00 \\
-\end{array}$ & $\begin{array}{c}0.00 \\
-\end{array}$ \\
\hline$\gamma$ & $\begin{array}{l}-0.32 * * \\
(0.03)\end{array}$ & $\begin{array}{l}-0.14 \\
(0.21)\end{array}$ \\
\hline$J(16) p$-value & 0.897 & 0.793 \\
\hline
\end{tabular}

Specification: $i_{t}=(1-\rho)\left[\left(i^{*}-c_{1} \pi^{*}\right)+c_{1} \pi_{t}+c_{2} y_{t}+c_{4} y_{t}^{2}\right]+\rho i_{t-1}+v_{t}$

Notes: Standard errors using a four lag Newey-West covariance matrix are reported in brackets. Inflation is measured as the change in the consumer price index (cpi) and the output gap is obtained using the CBO potential output. The instrument set includes four lags of cpi inflation, cbo output gap, squared cbo output gap, the fed funds rate and the rate of change in the gdp deflator. The asymmetric preference parameter on inflation is restricted to zero while the one on the output gap is computed as $\gamma=2 \mathrm{c}_{4} / \mathrm{c}_{2}$. The standard errors are obtained using the delta method. $J(m)$ refers to the statistics of Hansen's test for $m$ overidentifying restrictions which is distributed as a $\chi^{2}(m)$ under the null hypothesis of valid overidentifying restrictions. The superscript $* *$ and $*$ denote the rejection of the null hypothesis that the true coefficient is zero at the 1 percent and 5 percent significance levels, respectively. 


\begin{tabular}{ccc} 
Average Inflation Bias & $1.11^{* *}$ & 0.32 \\
& $(0.12)$ & $(0.48)$ \\
& $3.61^{* *}$ & $2.77^{* *}$ \\
Inflation Target & $(0.31)$ & $(0.25)$ \\
& $4.72^{* *}$ & $3.09^{* *}$ \\
Model-Based & $(0.26)$ & $(0.50)$ \\
Inflation Mean & & \\
\hline \multirow{2}{*}{$\begin{array}{c}\text { Actual Inflation Mean } \\
\text { Standard Deviation } \\
\text { of the Output Gap }\end{array}$} & 4.5 & 2.8 \\
\hline \hline
\end{tabular}

Model-based inflation mean: $E\left(\pi_{t}\right)=\pi^{*}-\frac{c_{4}}{c_{1}} \sigma_{y}^{2}=\pi^{*}-\frac{\gamma \lambda}{2 \kappa} \sigma_{y}^{2}$

Notes: Standard errors in brackets. The average inflation bias, which is defined as the difference between the model-based average inflation and the inflation target, is recovered from the estimates of the interest rate reaction function reported in Table 6 as $\left(-\mathrm{c}_{4} \sigma_{\mathrm{y}}^{2} / \mathrm{c}_{1}\right)$. The standard errors are obtained using the delta method. The superscript ** and $*$ denote the rejection of the null hypothesis that the true coefficient is zero at the 1 percent and 5 percent significance levels, respectively. 
Figure 1: Preference over Output Stabilization

- cubic vs. quadratic -

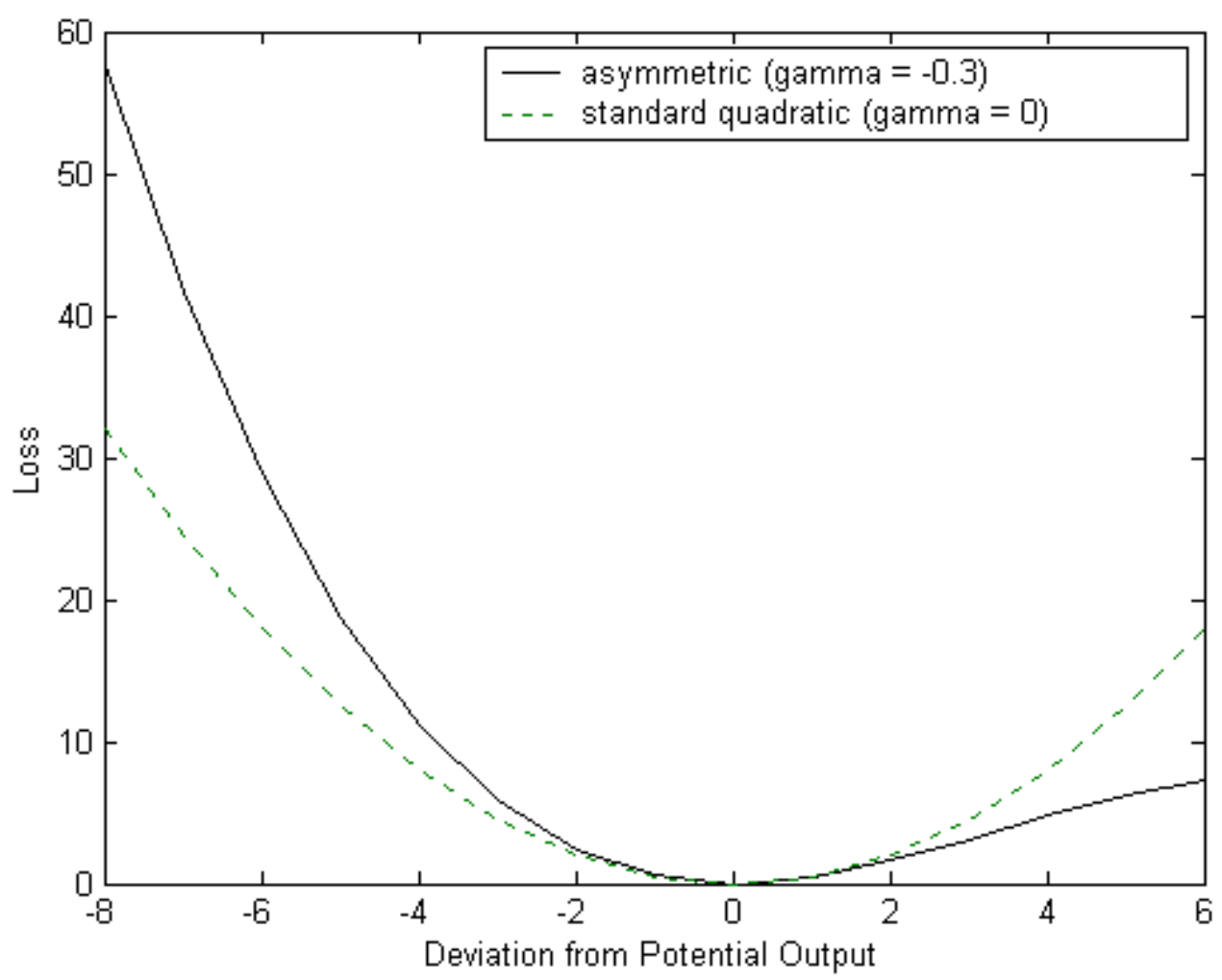

The horizontal axis spans the range of historical values for the CBO output gap during the sample 1960:1 - 2003:2 while the value of gamma in the asymmetric specification is consistent with the estimates reported below. 
Figure 2: Federal Funds Rate, CPI Inflation and CBO Output Gap
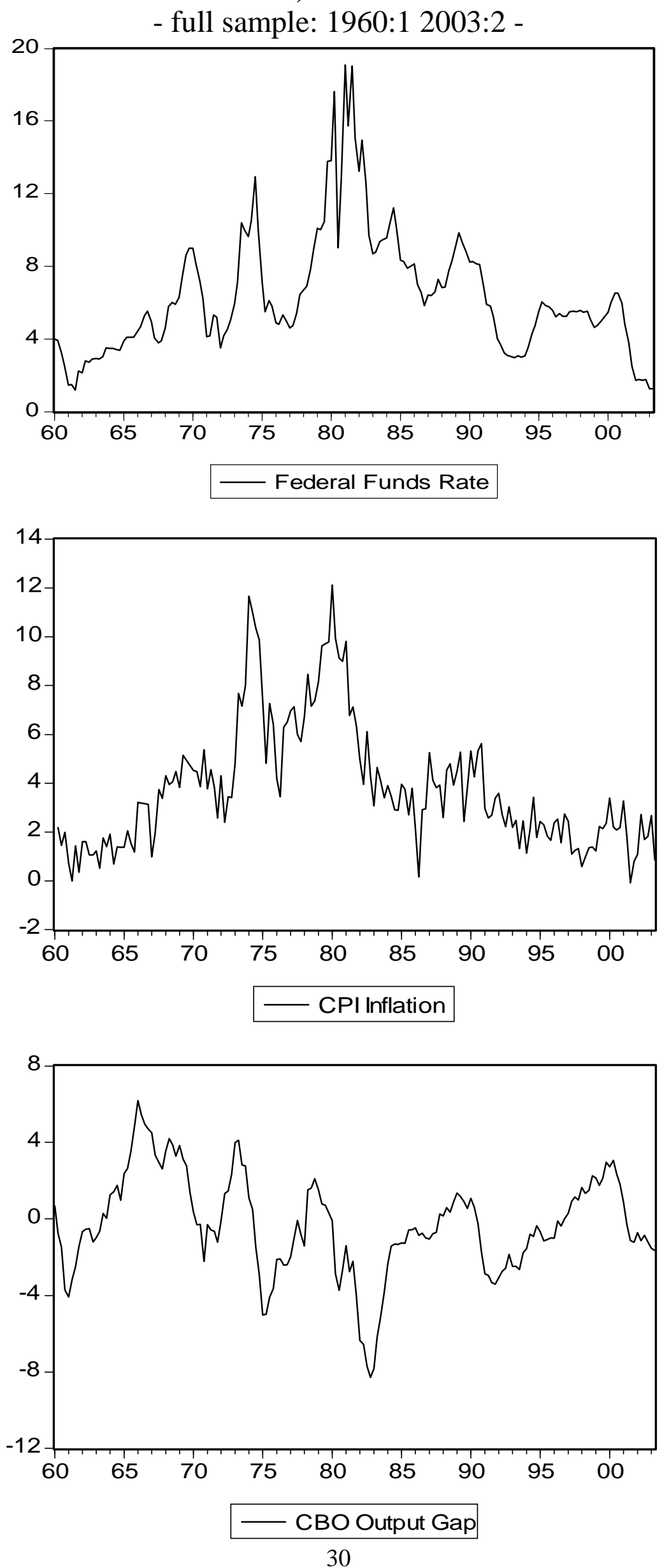